\title{
ANALYSIS OF ASAR/ENVISAT POLARIMETRIC BACKSCATTERING CHARACTERISTICS OF DONANA NATIONAL PARK WETLANDS
}

\author{
B. Marti-Cardona ${ }^{(1)}$, C. Lopez-Martinez ${ }^{(2)}$,J. Dolz-Ripolles ${ }^{(1)}$ \\ ${ }^{(1)}$ Flumen Research Group, Technical University of Catalonia (UPC), Barcelona, Spain, belen.marti@upc.edu \\ ${ }^{(2)}$ Remote Sensing Lab, Technical University of Catalonia (UPC) \& Institut d'Estudis Espacials de Catalunya (IEEC-CRAE), Barcelona
}

\begin{abstract}
Doñana National Park wetlands, in Southwest Spain, undergo yearly cycles of inundation and drying out. These cycles, together with great extensions of annual helophytes, make of Doñana a rapidly changing environment. 43 ASAR/Envisat images of Doñana in $\mathrm{HH}, \mathrm{VV}$ and $\mathrm{HV}$ polarizations were acquired throughout the hydrological year 2006/07 with the aim to monitor in detail an entire flooding cycle. The images were ordered in the seven ASAR swaths to achieve high observation frequency.

Backscattering temporal signatures of two main land cover types were obtained in the three polarization configurations and six ASAR swaths. Polarimetric behavior of the signatures is analyzed with the aid of extensive site data, such as a precise digital elevation model and continuous records of water level and meteorological parameters. Conclusions on the feasibility to discriminate emerged versus flooded land are derived for the different incidence angles, land cover types and phenological stages.
\end{abstract}

Index Terms - Synthetic aperture radar, polarimetry, water resources, monitoring.

\section{INTRODUCTION}

Doñana National Park marshes, in South West Spain, extend over the antique Guadalquivir River estuary, on the Atlantic Ocean coast. Doñana is notable for the great diversity of its biotopes and constitutes a crucial passage and breeding site for hundreds of thousands of migratory birds each year.

In 1998 the Spanish Ministry of the Environment promoted the project called Donana 2005, aimed at the restoration of the marshes natural hydrological scheme, deeply altered during most of the XX century. Within the frame of Doñana 2005 the Flumen Research Group, at the Technical University of Catalonia, was commissioned to develop and calibrate a hydrodynamic model of the marshes, able to predict the wetland response to proposed actions in the Guadalquivir River basin. The rigorous calibration of the hydrodynamic model required synoptic observations of the marshes flood extent along one hydrological year, with higher temporal resolution during the rainfall period. In order to obtain these observations, Flumen acquired from 43 Doñana images of the Synthetic Aperture Radar sensor (ASAR), on board of the Envisat satellite, during the hydrological year 2006/07 (i.e. from September 2006 to August 2007).
In this study backscattering temporal signatures of Doñana main land cover types were obtained for $\mathrm{HH}, \mathrm{VV}$ and $\mathrm{HV}$ polarizations and for six ASAR swaths. Polarimetric behavior of the signatures is analyzed with the support of site data, such as a digital elevation model, continuous records of water level and meteorological parameters at five permanent gauging stations and ground truth data concurrent with the image acquisitions. Since the distribution of the main land cover classes in Doñana is known, the analysis does not focus on the classes' spatial discrimination but on the effect of the inundation on each class backscattering characteristics, with the final objective to derive flood maps from the ASAR images.

So far, flood delineation from the imagery has allowed observing the wind drag action on Doñana water bodies and to calibrate this effect in the hydrodynamic model. The evaporation and infiltration losses rate has also been estimated from ASAR observations and incorporated into the model.

\section{STUDY SITE}

Doñana National Park is located in South West Spain, on the banks of the Guadalquivir River, near its mouth on the Atlantic Ocean coast. 27,000 ha of the National Park, approximately half of its extension, are marshland area. The marshes undergo a yearly cycle of inundation in autumn and drying out during the spring season and its flood extension varies considerably among years depending on the precipitation [1].

The topography of the marshes is extremely flat, with a maximum elevation difference of $2.50 \mathrm{~m}$ and slope smaller than $1.3 \%$ in $98 \%$ of the area. Despite its subtleness, the marshes relief has a critical effect on the hydroperiod or time that each zone remains flooded, which in turn determines the vegetal species growing in it [3].

Adapting to ASAR discrimination capability, Doñana marshes can be subdivided into three area types, paciles, ponds centers and transition zones, which are described as follows:

- The deepest marshland areas, the centers of ponds and watercourses, are the first ones in flooding and the last ones in drying out. In other words, they are the areas of longer hydroperiod. The centers of the ponds are formed by clayey bare soil, and virtually no vegetation develops in them at any time of the year.

- The locally called paciles, the most elevated zones, are fluvio-tidal sediment bars located between ponds and watercourses. The paciles only flood in wet years, when the water level in the marshes rises high enough. The vegetation found in the 
paciles is pasture land, locally known as almajar. The almajar is dominated by the almajo plant or Arthrocnemun macrostachyum, shrub of height comprised between 0.5 and $1.1 \mathrm{~m}$, and percentage of coverage around $50 \%$ [3]. When flooded, the water depth in the paciles rarely exceeds $0.3 \mathrm{~m}$, so most of the almajo bush remains out of the water.

- The transition zones, between paciles and the ponds centers, are colmated watercourses. They flood almost every year, and communities of large helophytes develop in them [3]. These plants start emerging from the water surface around the end of February, experience spectacular growth throughout the spring season and dry out and die during the summer. Their brown stems stick out of the water surface when the marshes flood in autumn, but they progressively putrefy and disappear under water by the spring.

\section{DATA}

In September 2002 a LIDAR survey flight was conducted over Doñana and allowed the generation of a digital terrain model (DTM) of $2.00 \mathrm{~m}^{2}$ and $0.15 \mathrm{~m}$ planimetric and elevation resolution respectively. A network of five permanent hydrometeorological gauging stations was installed in September 2004. These stations take continuous measurements of water level, water temperature, conductivity, dissolved oxygen, rainfall, wind direction and velocity, air temperature and humidity, soil temperature and incident and reflected visible and near infrared radiation.

This study focuses on the hydrological year 2006/07 because it was a wet year in which the paciles flooded partially, and also because continuous series of water level and meteorological data were registered at the above mentioned stations.

The Flumen group acquired 43 ASAR images of Doñana marshes in Alternating Polarization mode from September 2006 to July 2007. The ASAR sensor is installed on board of the Envisat satellite of the European Space Agency (ESA), which has a repeat cycle of 35 days [2]. ASAR images the Earth by transmitting and receiving electromagnetic radiation at $\mathrm{C}$ band $(5.34 \mathrm{GHz})$ and, when operating in the Alternating Polarization mode, has a spatial resolution of $30 \mathrm{~m}$. In this mode ASAR acquires images by scanning between two of the three polarization channels as follows: $\mathrm{HH}, \mathrm{VV}$ and $\mathrm{HV}$, and its imaging swath can be selected by changing the beam incidence angle and the elevation beamwidth. There are seven predetermined swaths designated as IS1 to IS7 from smaller to larger beam incidence angles. Table 1 shows the incidence angle range for each swath.

ASAR's pointable capability enables up to 14 image acquisitions of Doñana per 35-day orbit cycle. The images were ordered in the seven ASAR swaths to achieve a high temporal resolution, especially during the fall, when the marshes rapidly fill with water. Ascending and descending tracks were used indifferently, in virtue of the terrain flatness and the horizontal isotropy of the vegetation. The ASAR Alternating Polarization mode and the polarization configuration for each image acquisition were chosen in accordance with previous works assessing ASAR's suitability for monitoring Doñana marshes [6]. However, some of the requested image acquisitions were rejected or had to be modified because of conflicts with other ASAR users orders.
The number of image acquisitions per swath is summarized in Table 1. Swath IS5 experienced technical irregularities during the study period, so it has not been used in this study. Ground truth data were collected coinciding with ASAR image acquisitions over Doñana. Other ancillary data included Landsat images and vegetation thematic maps.

Table 1. Incidence angle range of ASAR swaths and number of image acquisitions per swath and polarization.

\begin{tabular}{|c|c|c|c|}
\hline ASAR swath & $\begin{array}{c}\text { Incidence } \\
\text { Angle Range ( }\end{array}$ & $\begin{array}{c}\text { Number of } \\
\text { Images }\end{array}$ & Polarization \\
\hline IS1 & $15.0-22.9$ & 5 & $\begin{array}{c}4 \text { in HH/HV, 1 } \\
\text { in HH/VV }\end{array}$ \\
\hline IS2 & $19.2-26.7$ & 6 & $\mathrm{HH} / \mathrm{VV}$ \\
\hline IS3 & $26.0-31.4$ & 8 & $\begin{array}{c}2 \text { in HH/HV, 6 } \\
\text { in HH/VV }\end{array}$ \\
\hline IS4 & $31.0-36.3$ & 8 & $\mathrm{HH} / \mathrm{VV}$ \\
\hline IS5 & $35.8-39.4$ & 3 (not used) & $\mathrm{HH} / \mathrm{VV}$ \\
\hline IS6 & $39.1-42.8$ & 9 & $\mathrm{HH} / \mathrm{VV}$ \\
\hline IS7 & $42.5-45.2$ & 7 & $\mathrm{HH} / \mathrm{VV}$ \\
\hline
\end{tabular}

\section{METHODS}

All the images were received from ESA as radar brightness and georeferenced (ASA_APG_1P product). The radar backscattering coefficient $\left(\sigma^{0}\right)$ at each image pixel was computed according to [7]. For applying this calibration flat terrain was assumed, i.e., the increment of incidence angle due to the terrain slope was neglected. The maximum $\sigma^{\mathrm{o}}$ error introduced by this simplification was assessed, being of $5 \%$ in areas with slope higher than $1.3 \%$ (less than $2 \%$ of the marshes extent) in IS1 images. The error decreases below $1 \%$ for the same areas in IS7 images.

Once the images were calibrated, 15 regions of interest (ROIs) representative of the main land cover types in Doñana were defined. These ROIs include roughly 1,000 pixels each (15.6 ha), and were selected so that they comprised approximately flat areas with homogeneous vegetation. The definition of the ROIs was as follows:

- 3 out of the 15 ROIs are located in the ponds centers and characterize the land cover class designated as Deep Bare Soil.

5 ROIs are located in the paciles. 2 of them were defined in areas of almajar that flooded during the hydrologic year 2006/07 and have been designated as Low Almajar. The other 3 occupy slightly higher areas which did not flood and represent the class High Almajar.

7 ROIs were defined in the transition zones, but the analysis of these classes is not included in this paper.

Ground truth data plus the DTM and the water levels measured at the gauging stations were used to determine the dates on which the different ROIs flooded and unflooded during the study period. The backscattering coefficient arithmetic mean of the pixels in each ROI was computed for the two polarizations of the 43 images. Plots showing the average coefficient evolution for each class, swath and polarization along the hydrological year 2006/07 were drawn. Observations about the classes' different backscattering behavior before, during and after the inundation are presented in the next section. These observations, as well as the classes mean backscattering values, are currently being used for flood surface classification of the ASAR images. 


\section{RESULTS AND DISCUSSION}

\subsection{Land Cover Class: Deep Bare Soil}

Deep Bare Soil ROIs consist on either even clayey soil or open water. The dominant backscattering mechanism in both cases is surface scattering. Consistently with this mechanism, the temporal signatures of this class show higher $\sigma^{0}$ in $\mathrm{VV}$ than in $\mathrm{HH}$ polarization in all swaths both before and after the inundation (Figure 1), with a rather stable ratio $\sigma^{0} \mathrm{HH} / \sigma^{0} \mathrm{VV}$ ranging between 0.5 and 0.8 in the large majority of the images.

The ROIs of the class Deep Bare Soil were emerged in only 8 of the 43 ASAR images, in swaths IS1, IS3, IS4 and IS6. In all cases the backscattering coefficient of the emerged bare soil was higher than that from the flooded surface in the same swath and polarization (Figure 1). $\sigma^{0}$ differences between emerged and flooded Deep Bare Soil are slightly lower in $\mathrm{HH}$ than in $\mathrm{VV}$ polarization, and have a minimum value on windy days due to the increased backscattering of the wind-roughened water surface [8]. The minimum observed $\sigma^{0}$ change between flooding stages is: 1.9 $\mathrm{dB}$ in swath IS6, 3.2 in IS4, 2.6 in IS3 and 0.6 in IS1. The reduced $\sigma^{0}$ difference in IS1 is explained by the higher sensitivity of steep incidence angles to the water surface roughness [8]. In the case of IS6 images, the shallow incidence angle causes high specular reflection of the radar beam not only on the open water but also on the smooth bare clayey soil [4]. This results in lower $\sigma^{0}$ differences between emerged and flooded surface in IS1 and IS6 compared to those in IS3 and IS4.

The number of cross-polarized data is limited to 6 images in swaths IS1 and IS3, one previous to the inundation in each swath. $\sigma^{0} \mathrm{HV}$ values are in all cases close or below the ASAR noise equivalent $\sigma^{0}$ value (about $-20 \mathrm{~dB}$ ). The backscattering mechanism of the Deep Bare Soil class is surface scattering on a relatively smooth surface throughout the study period. This mechanism induces little depolarization of the electromagnetic radiation [4], what explains the low observed $\sigma^{0} \mathrm{HV}$ values.

\subsection{Land Cover Classes: High Almajar and Low Almajar}

The High Almajar ROIs did not flood in the hydrological year $2006 / 07$, although they occasionally became swamped after strong rainfall events, such as the one on 28 January 2007 (Figure 2). The ROIs of class Low Almajar were flooded approximately from 11 November 2006 to 29 May 2007.

Right after the summer the soil is very dry everywhere in the paciles and therefore the backscattering from the Low and High Almajar is analogous (Figures 2 and 3).

A similar backscattering temporal pattern is observed in the High Almajar ROIs for all swaths: $\sigma^{\circ} \mathrm{HH}$ and $\sigma^{\circ} \mathrm{VV}$ take their lowest values at the beginning of the hydrological year, when the soil is very dry, and so does the $\sigma^{0} \mathrm{HH} / \sigma^{0} \mathrm{VV}$ ratio. Backscattering and ratio increase during the marshes flooding period, presumably due to the higher soil humidity, and go down again from April on,

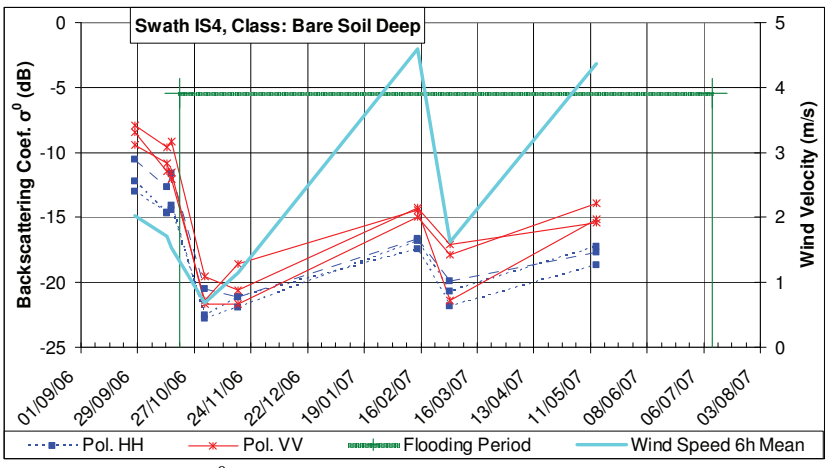

Fig. 1. IS4 $\sigma^{0}$ temporal signature of class Deep Bare Soil.

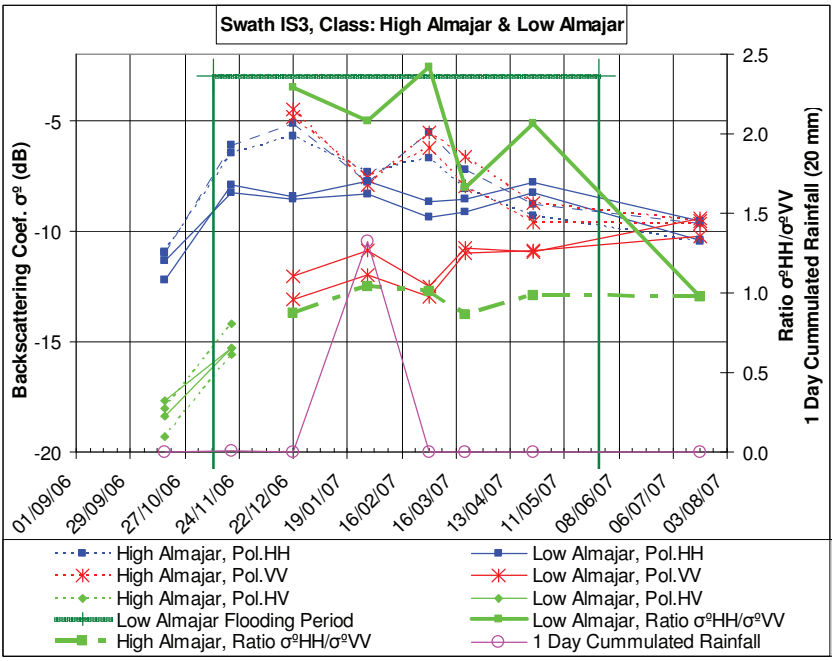

Fig. 2. IS $3 \sigma^{0}$ temporal signature of classes High and Low Almajar

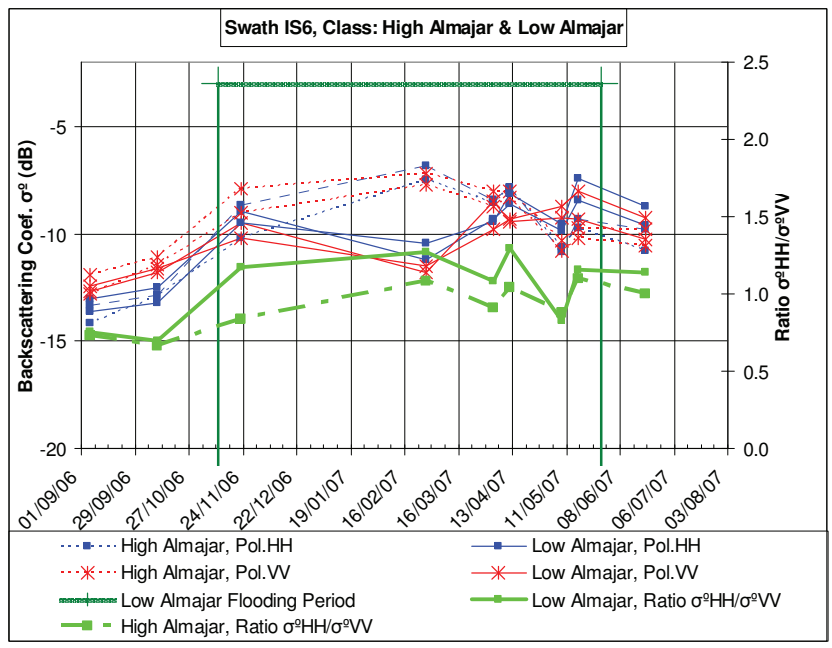

Fig. 3. IS6 $\sigma^{0}$ temporal signature of classes High and Low Almajar

when the soil progressively dries out. No effect of the incidence angle is observed on the $\sigma^{0} \mathrm{HH} / \sigma^{0} \mathrm{VV}$ ratio, except that it seems to be more variable in swath IS2.

When the Low Almajar floods, $\sigma^{0} \mathrm{HH}$ and $\sigma^{0} \mathrm{VV}$ decrease in all swaths respect to those of the High Almajar (Figures 2 and 3). 
As mentioned before, the almajo bush coverage is around $50 \%$. The remaining $50 \%$ is occupied by bare soil and short pasture, whose dominant backscattering mechanism is surface scattering. When the Low Almajar floods, soil and pasture are covered by water. The surface of these open water portions remains rather smooth even on windy days, due to the low water depth and the shelter effect of the almajo bushes. The specular reflection of the radar beam on the smooth open water portion of the flooded Low Almajar explains the $\sigma^{0}$ decrease of this class after flooding.

The backscattering decrease is more pronounced in VV than in HH polarization and for swaths IS2, IS3 and IS4 (there are not enough data for IS1). Thus, the ratio $\sigma^{0} \mathrm{HH} / \sigma^{0} \mathrm{VV}$ in these swaths increases with the inundation from values below 1.0 to values between 1.4 and 2.7. This differential behavior between polarizations can be explained by larger almajo canopy-water surface interactions at $\mathrm{HH}$ than at VV polarization [10], and by a higher penetration capacity at $\mathrm{VV}$, which therefore experiences more forward reflection on the water surface.

At large incidence angles the path length through the almajo bush increases, and so does the canopy microwave energy attenuation [10],[5]. Less radiation can penetrate the plant and interact with the water surface underneath, what explains the reduced difference between $\mathrm{HH}$ and VV signatures observed in IS6 and IS7. On the other hand, the backscattering decrease of the Low Almajar, where soil and pasture are under water, respect to that of the High Almajar, with emerged soil and pasture, is smaller in IS6 and IS7 than in other swaths. This reduced difference might be due to the fact that the emerged soil and short pasture $\sigma^{0}$ decreases with incidence angle [9], thus getting closer to the low backscattering of the same surface when flooded.

Soon after the flooding period, in June, the ratio $\sigma^{0} \mathrm{HH} / \sigma^{0} \mathrm{VV}$ of the Low and High Almajar takes again similar values, but the backscattering coefficient from the Low Almajar is, greater than that from the High Almajar (Figure 3) due, presumably, to the rather higher humidity of the just unflooded soil.

\section{CONCLUSIONS}

The backscattering coefficient of the class Deep Bare Soil has been observed to decrease with inundation in all swaths and polarizations, while the ratio $\sigma^{0} \mathrm{HH} / \sigma^{0} \mathrm{VV}$ stays stable along the flooding cycle. Images of the emerged Deep Bare Soil are only available in swaths IS1, IS3, IS4 and IS6. Temporal signatures in these swaths, together with 2D scatter plots of $\sigma^{0} \mathrm{HH}$ versus $\sigma^{0} \mathrm{VV}$ (not included in this document) indicate clear separability between flooding stages in swaths IS3 and IS4. High backscattering from wave action at steep incidence angles can cause confusion between flooded and emerged soil in IS1 imagery on windy days. IS6 $\sigma^{0}$ of the bare soil can be almost as low as that of the flooded surface due to high proportion of specular reflection of both cover types at large incidence angles.

High and Low Almajar temporal signatures are clearly separable during the flooding period in swaths IS2 to IS4. The main indicator of this class inundation is the steep increase in the $\sigma^{0} \mathrm{HH} / \sigma^{0} \mathrm{VV}$ ratio, as a result of a large decrease in $\sigma^{0} \mathrm{VV}$ compared to that in $\sigma^{0} \mathrm{HH}$. Ratios below 1.1 denote emerged almajar in the abovementioned swaths. The smaller the incidence angle the higher the $\sigma^{0} \mathrm{HH} / \sigma^{0} \mathrm{VV}$ value and therefore the distinction of flooded versus emerged almajar areas on a single image.

Classes characteristic of the transition zones were also defined and analyzed, but a comprehensive description of these classes behavior exceeds the scope of this paper.

This study's results on Doñana wetlands polarimetric and multiswath backscattering characteristics are currently being used to derive Doñana flood maps from ASAR images, which in turn, make possible the calibration of the marshes hydrodynamic model.

Doñana continuous and precise ground truth data sets offer a valuable opportunity for the research of remote sensing applications to hydrology and wetland monitoring and management, and it is the aim of the authors to continue this line of research.

\section{REFERENCES}

[1] L. Clemente, L. Ventura-García, J.L. Espinar, J.S. Cara and A. Moreno, "Las Marismas del Parque Nacional Doñana", Investigación y Ciencia, Prensa Científica, Barcelona, 2004.

[2] Environmental Space Agency, Envisat ASAR Product Handbook, Is.2.1, ESA, 2006.

[3] García, J.I., J.A. Mintegui, and J.C. Robredo, La Vegetación en la Marisma del PN de Doñana en Relación con su Régimen Hidráulico, Ministerio de Medio Ambiente, Madrid, 2005.

[4] Henderson, F.M. and A.J. Lewis, Principles and Applications of Imaging Radar, John Wiley \& Sons, New York, 1998.

[5] P. Kandus, H. Karszenbaum, T. Pultz, G. Parmuchi and J. Bava, "Influence of Flood Conditions and Vegetation Status on the Radar Backscatter of Wetland Ecosystems", Canadian Journal of Remote Sensing, Canadian Aeronautics and Space Institute, 2001.

[6] B. Marti-Cardona, J. Dolz-Ripolles, J. Gili-Ripoll, "Monitoring of the Flooding and Dry-Out Processes in Doñana National Park for the Calibration of the Hydrodynamic Model of its Marshes", Proceedings of GlobWetland Symposium: Looking at Wetlands from Space, European Space Agency, Frascati, 2006.

[7] B. Rosich, and P. Meadows, "Absolute Calibration of SAR Level-1 Products Generated with PF-ASAR", ESA Technical Note version 1.4, 2004.

[8] J. Töyrä, A. Pietroniro and L. Martz, "Multisensor Hydrologic Assessment of Freshwater Wetland", Remote Sensing of Environment, Elsevier Science, New York, pp. 75:162-173, 2001.

[9] Ulaby, F.T. and M.C. Dobson, Handbook of Radar Scattering Statistics for Terrain. Artech House, Norwood MA, 1989.

[10] Y. Wang, L. Hess, S. Filoso and J.M. Melack, "Understanding the Radar Backscattering from Flooded and Nonflooded Amazonian Forests: Results from Canopy Backscatter Modeling”, Remote Sensing of Environment, Elsevier Science, New York, pp. 54:324-332, 1995. 